Linguagens - Revista de Letras, Artes e Comunicação - ISSN 1981-9943

Blumenau, v. 12, n. 2, p. 327-346, maio/ago. 2018

DOI: http://dx.doi.org/10.7867/1981-9943.2018v12n2p327-346

\title{
TRAGO-TE FLORES: MORTE, IMAGENS E LINGUAGENS
}

\author{
Paula Andréa Caluff Rodrigues ${ }^{1}$ \\ Paulo Nunes Jorge Martins ${ }^{2}$
}

Trago-te flores - restos arrancados da terra que nos viu passar unidos e ora mortos nos deixa e separados.

(Machado de Assis) $^{3}$

\begin{abstract}
Resumo
As flores, com suas diferentes formas, cores e dimensões, têm lugar de destaque nas representações imaginárias tecidas pelo ser humano ao longo das eras. Inumações em sítios arqueológicos atestam sua presença ao lado de antigas sepulturas, sendo esse costume comum desde a pré-história até a atualidade. Este artigo apresenta um aprofundamento sobre este ícone específico na arte sepulcral e as diversas simbologias que ele carrega. A partir da pesquisa de campo em necrópoles brasileiras e portuguesas, complementadas por pesquisas bibliográficas sobre iconografia funerária, foi possível uma contextualização histórica e a elaboração de uma tabela das principais flores com simbologias ligadas à morte, com a exemplificação feita por meio de um túmulo do Cemitério da Soledade, em Belém do Pará. O artigo demonstra a importância de estudos semióticos para o entendimento de linguagens não verbais, como uma forma de comunicação, presentes notadamente em cemitérios históricos, como forma de valorização e preservação de seu patrimônio e de sua memória.
\end{abstract}

Palavras-chave: Iconografia funerária. Cemitérios. Simbologia. Flores. Linguagens.

\section{BRING YOU FLOWERS: DEATH, IMAGES AND LANGUAGES}

\begin{abstract}
The flowers, with their different shapes, colors and dimensions, have a prominent place in the imaginary representations woven by the human being throughout the ages. Burials at archaeological sites attest to its presence beside burials, and this custom has been common from prehistory to the present day. This article presents a deepening on this specific icon in sepulchral art and the diverse symbologies that it carries. From field research in Brazilian and Portuguese necropolises, complemented by bibliographical researches on funerary

\footnotetext{
${ }^{1}$ Universidade da Amazônia (UNAMA), Belém - Pará - Brasil. Doutoranda em Comunicação, Linguagens e Cultura, pela Universidade da Amazônia - UNAMA, Mestre em Patrimônio Cultural pelo Instituto do Patrimônio Histórico e Artístico Nacional - IPHAN. Professora, Arquiteta e Urbanista. ORCID $<$ http://orcid.org/0000-0002-2504-1226>. E-mail: pacaluff@gmail.com.

${ }^{2}$ Universidade da Amazônia (UNAMA), Belém - Pará - Brasil. Doutor em Letras e Literatura em Língua Portuguesa pela Pontifícia Universidade Católica (PUC/MG). Pesquisador e Professor do Programa de PósGraduação em Comunicação Linguagem e Cultura na Universidade da Amazônia (UNAMA). E-mail: pontedogalo3@gmail.com.

${ }^{3}$ Trecho do soneto "A Carolina", escrito por Machado de Assis, quando da morte de sua esposa, com quem fora casado por 35 anos, em feliz união. Ver mais em: SANTOS, MAURO CAMILO DE CHANTAL; OLIVEIRA, ARNON SÁVIO REIS DE; OLIVEIRA, PATRÍCIA VALADÃO ALMEIDA DE. "A Carolina", soneto de Machado de Assis em música de Hostílio Soares. Machado Assis Linha, São Paulo, v. 9, n. 18, p. 2852, Aug. 2016. Disponível em: http://www.scielo.br/scielo.php ?script=sci_arttext\&pid=S198368212016000200028\&lng=en\&nrm=isso Acesso em: 13 apr 2020
} 


\section{Linguagens - Revista de Letras, Artes e Comunicação - ISSN 1981-9943 \\ Blumenau, v. 12, n. 2, p. 327-346, maio/ago. 2018 \\ DOI: http://dx.doi.org/10.7867/1981-9943.2018v12n2p327-346}

iconography, it was possible to contextualize the history and the elaboration of a table of the main flowers with symbologies linked to death, with the example made by means of a tomb of the "Cemiterio da Soledade", in Belem of Para. The article demonstrates the importance of semiotic studies for the understanding of nonverbal languages, as a form of communication, especially present in historical cemeteries, as a way of valuing and preserving its patrimony and memory.

Keywords: Funeral iconography. Cemeteries. Symbology. Flowers. Languages.

\section{INTRODUÇÃO: NO JARDIM DA MORTE, ONDE A VIDA EMURCHECE}

As flores têm lugar de destaque nas representações imaginárias tecidas pelo ser humano ao longo das eras. Para alguns, são simplesmente os órgãos sexuais das plantas, com seus pistilos e estames, conforme comprovou o cientista sueco Carolus Linnaeus, ainda no século XVIII (SAKS, 2017. p. 14). Para outros, são entes portadores de grande simbologia, sendo objetos, inclusive, de regras e códigos que precisam ser conhecidos para não causarem constrangimentos.

Uma publicação lusitana do século XIX, denominada Diccionário da Linguagem das Flores, estabelecia parâmetros a serem observados, em uma demonstração da importância que o tema assumia para as pessoas daquela época:

\footnotetext{
Para fazer uso da linguagem das flores poucas regras bastam. A primeira consiste em saber que uma flor apresentada direita exprime um pensamento, e que basta invertê-la para que represente o contrário; assim um botão de rosa de musgo com seus espinhos e folhas quer dizer: eu espero, mas receio; dando-se o mesmo botão voltado, significa: não ha que temer nem esperar. (DICCCIONÁRIO DA LINGUAGEM DAS FLORES, 1868. p.04)
}

Diferentes civilizações demonstraram ao longo da História, o uso das flores de maneira simbólica, a começar pelo homem primitivo. Pesquisas e inumações em sítios arqueológicos atestam sepultamentos de forma cerimoniosa, onde montes de terra, pedras, gravetos e até flores marcavam as covas, como um indicativo da preocupação com o post mortem e, ao mesmo tempo, a existência de uma intencionalidade de fazer memória ao morto, pois se marcavam o lugar era porque havia um desejo de ali retornar (MUMFORD, 1998).

Desde a antiguidade, povos hindus consideram algumas flores como "moradas passageiras da nynphas e da sylphides", adornando templos e corpos com elas. No antigo Egito, Amasis tornou-se general do Rei Partanis, após haver lhe oferecido uma coroa de flores. A flor de Liz adornava altares hebreus e coroou o rei Salomão. Os gregos associavam seus deuses a flores: Juno (flor de liz); Ceres (papoula); Apolo (jacinto); Baco (hera); Plutão 
(cipreste); e assim por diante (DICCCIONÁRIO DA LINGUAGEM DAS FLORES, 1868. p. $5-6)$.

As diversas religiões também se relacionam de maneira simbólica com as flores: o Cristianismo usa a imagem do lírio (pureza, inocência), das rosas (lembra o sangue de Cristo e a oração mariana denominada de Rosário) e da flor de liz (Nossa Senhora). Para o Hinduísmo, o nome puja, dado aos cultos rituais, pode ser traduzido como "ato de flores", sendo a flor de lótus a mais importante de todas, também venerada pelo Budismo. No Taoísmo e outras religiões chinesas as flores são símbolos da vida, felicidade e fertilidade (THE FLOWER EXPERT, 2018).

Este artigo, no entanto, trata especificamente do uso das flores em representações funerárias e busca analisar a linguagem que elas carregam na relação entre vida e morte. Estas imagens, esculpidas ou simplesmente depositadas em túmulos, podem ser consideradas como um detalhe poético que decora as sepulturas e mausoléus, e que também falam sobre virtudes, sentimentos e aceitação. As flores de cemitérios, naturais ou em representações escultóricas, são imagens que expressam desejos e outros sentimentos. Os dados levantados e ora apresentados condensam alguns anos de pesquisas nesses 'museus fúnebres', que contribuíram para a abordagem, neste artigo, de apenas um elemento simbólico: as flores.

O Cemitério N. Sra. da Soledade, inaugurado em 1850, em Belém/PA e tombado pelo Instituto do Patrimônio Histórico e Artístico Nacional - IPHAN, em 1964, serve de base para este estudo. Trata-se de um cemitério inspirado nos modelos europeus da época, em geral, considerados museus a céu aberto, em virtude do grande número de construções e esculturas de arte funerária.

Este artigo foi originado a partir da necessidade de um maior aprofundamento sobre os signos presentes na morte, com os ícones e símbolos que dela derivam, presentes na arte sepulcral, notadamente em cemitérios monumentais do século XIX. A partir de pesquisas de campo em necrópoles, foram tecidas as considerações confrontadas com o material obtido em estudos teóricos complementares, que resultam na análise de alguns tipos de imagens de flores com caráter fúnebre.

A investigação gira em torno de representações típicas do Novecentos, quando houve a apoteose da arquitetura e escultura funerárias, inspiradas pelo Romantismo. Alguns autores consideram o período entre 1860 até 1930, como a época áurea das produções funerárias na Europa, América do Norte e América do Sul (VOVELLE, 1997). Os ideais iluministas, advindos do século anterior, inflamaram discussões de caráter higienista que culminaram com 


\section{Linguagens - Revista de Letras, Artes e Comunicação - ISSN 1981-9943 \\ Blumenau, v. 12, n. 2, p. 327-346, maio/ago. 2018 \\ DOI: http://dx.doi.org/10.7867/1981-9943.2018v12n2p327-346}

a proibição dos sepultamentos dentro das igrejas. É o fim de um costume que ocorria desde os primeiros séculos, atravessou o Medievo e chegou ao início da Idade Moderna. (FERREIRA, 2009).

Com a secularização, fica proibido sepultamento eclesiástico e surgem os primeiros cemitérios públicos. Por um lado, houve uma rejeição inicial e demora na aceitação de transgressão de um costume secular. Por outro lado, a partir do momento em que não havia mais o controle da Igreja, tanto os artistas como os consumidores de sua arte, puderam escolher os mais variados temas, muitos dos quais não seriam aceitos dentro de um ambiente eclesiástico. "Cada túmulo assume características e identidades próprias". (CYMBALISTA, 2002. p. 72).

A "morte burguesa" é instaurada, permeada de dramaticidade, quando a arte sepulcral passa a buscar representações do triunfo da vida sobre a morte. Para isso, eram utilizados tanto elementos cristãos, quanto antigas fórmulas pagãs e profanas. Os cemitérios expandiram seu caráter religioso e se tornaram espaços sociais e culturais. (BORGES, 2002). Além de cruzes, anjos e figuras alegóricas, as flores, com sua riqueza de significados, são representações muito frequentes em cemitérios históricos.

Assim é que, este artigo, apresenta-se da seguinte forma: Introdução do tema, no qual são explicitados a problemática, os aspectos históricos e o objetivo da pesquisa; Metodologia utilizada; Discussão, dividida em três tópicos: Representações Fúnebres, Linguagem Alegórica e Caso da Lulu, um exemplo prático; e as Considerações Finais, que relatam o alcance dos objetivos, comprovando a importância da cognição da linguagem simbólica encontrada nas flores, como uma forma de comunicação e linguagem entre vivos e mortos.

No século XIX, morte e flores se relacionavam nas palavras, como visto no poema de Victor Hugo: "Dos vivos esquecidos fora, a natura é do morto:/ e no jardim da morte, onde a vida emmurchece,/ a alma esparge um olhar de celeste conforto;/ é meiga a flor; e da ave o cântico enternece". (REVISTA DOS MUNUMENTOS SEPULCRAES, 1869. p. 47). De igual maneira, morte e flores se relacionavam nas esculturas funerárias, como uma forma de deixar marcada nas sepulturas uma mensagem simbólica para ser lida posteriormente. Desse modo, o presente artigo procura discutir e entender melhor que mensagens são transmitidas por essas representações imagéticas funerárias em forma de flores.

\section{METODOLOGIA: PARA DIZER QUE FALEI DE FLORES}




\section{Linguagens - Revista de Letras, Artes e Comunicação - ISSN 1981-9943 \\ Blumenau, v. 12, n. 2, p. 327-346, maio/ago. 2018 \\ DOI: http://dx.doi.org/10.7867/1981-9943.2018v12n2p327-346}

De acordo com os procedimentos metodológicos, ressalta-se que, o objeto de estudo deste artigo resulta de investigações exploratórias desenvolvidas em alguns cemitérios históricos do século XIX: Cemitério Nossa Senhora da Soledade (Belém/PA); Cemitério dos Prazeres (Lisboa/PT) e Cemitério do Alto de São João (Lisboa/PT). Foram levantadas as principais iconografias funerárias existentes, com o objetivo de criação de uma base de dados, onde, pode-se destacar que o Cemitério da Soledade, em Belém do Pará, foi a principal fonte de informação in loco. Definiu-se então que seriam analisadas apenas as flores, a partir de um recorte de todos os dados imagéticos compilados, por meio de seleção do material específico, adotado na construção deste artigo.

Uma pesquisa bibliográfica e documental favoreceu o embasamento da temática da morte, em que alguns autores serviram de referência: Philippe Ariès (1977) Michel Vovelle (1997), Simões Ferreira (2009), Renato Cymbalista (2002), dentre outros. Esta parte do estudo referenciou as relações e sentidos que as imagens usadas em cemitérios contêm e como elas vinham sendo utilizadas ao longo do tempo.

Foram também realizadas investigações complementares em estudos semióticos, de iconografia e simbologia, em autores como Lúcia Santaella (1985), Panofsky (1992), Sarah Carr-Gomm (2004), Granviers e Jacomet (2003), dentre outros. Outra fonte importante de sustentação à pesquisa foi o Diccionário da Linguagem das Flores, publicação portuguesa que oferece um panorama da visão simbólica adotada no século XIX, período em que surgiram os cemitérios denominados monumentais.

Para investigação de campo, definiu-se no Cemitério da Soledade, o túmulo de Luiza Calandrini Dewey, que tem uma representação floral com intenção simbólica: a rosa em botão quebrada. O enfrentamento de bases teóricas (bibliográficas e documentais) e práticas (pesquisa de campo) resultou em um aprofundamento sobre arte sepulcral, simbologia funerária e estudos semióticos, em que o uso de imagens de flores foi enfatizado como forma de comunicação não verbal, permeada de significações.

\section{DISCUSSÃO: O CRAVO BRIGOU COM A ROSA?}

As questões, a seguir, são tratadas isoladamente, mas fazem parte do processo de desenvolvimento da pesquisa, pois, a partir da pesquisa documental e teórica sobre as flores, foi possível desenvolver uma análise sobre suas representações, apresentadas, de forma prática, ao final deste capítulo. 


\section{Linguagens - Revista de Letras, Artes e Comunicação - ISSN 1981-9943 \\ Blumenau, v. 12, n. 2, p. 327-346, maio/ago. 2018 \\ DOI: http://dx.doi.org/10.7867/1981-9943.2018v12n2p327-346}

\subsection{REPRESENTAÇÕES FÚNEBRES: FESTA DAS FLORES, MONARCA}

No século XVIII, um livreto ilustrado com imagens emblemáticas e uma série de poemas e sermões, celebrou a pompa funeral da Rainha Maria Sofia Isabel de Neoburg, falecida em 04 de agosto de 1699, aos 32 anos de idade. Era a segunda esposa de D. Pedro II, com quem foi casada por 12 anos e teve 07 filhos. "A sua morte causou a maior consternação tanto na corte, como no povo, que deveras a estimava. Foi sepultada, levando o hábito de S. Francisco, no panteão real de S. Vicente de Fora" (PORTAL DA HISTÓRIA, s/d).

A imagem de um maço de rosas com espinhos, sendo uma delas em botão (Figura 1), antecede um dos poemas ofertados, que inicia com o mote Festa das flores, Monarca. O relato fala do triste acontecido, associando a rainha de Portugal com a rainha das flores: a rosa.

\footnotetext{
Alerta, flores, alerta / que a morte vizita as flores / \& apontando seus rigores/ à Rainha flor acerta:/ Alma que dorme, desperta/ se de Christo tens a marca/ vendo a roza entregue à Parca/ não duvides da cahida;/ pois acabou hoje a vida/ cita das flores Monarca./ Esta roza, que a Rainha/ se chamou de todo o prado, / acabou o seu reinado,/ perdeo o bello que tinha,/ morreo a flor entre a espinha/ depóz a regia Coroa/ \&somente o eco soa/ dizendo desta agonia:/ acabou a flor que havia/ neste Vergel de Lisboa. (PAYVA, 1699. p. 9).
} 


\section{Linguagens - Revista de Letras, Artes e Comunicação - ISSN 1981-9943 \\ Blumenau, v. 12, n. 2, p. 327-346, maio/ago. 2018 \\ DOI: http://dx.doi.org/10.7867/1981-9943.2018v12n2p327-346}

Figura 1. Ilustração do livro celebrativo das Exéquias de D. Maria Sofia de Neoburg.

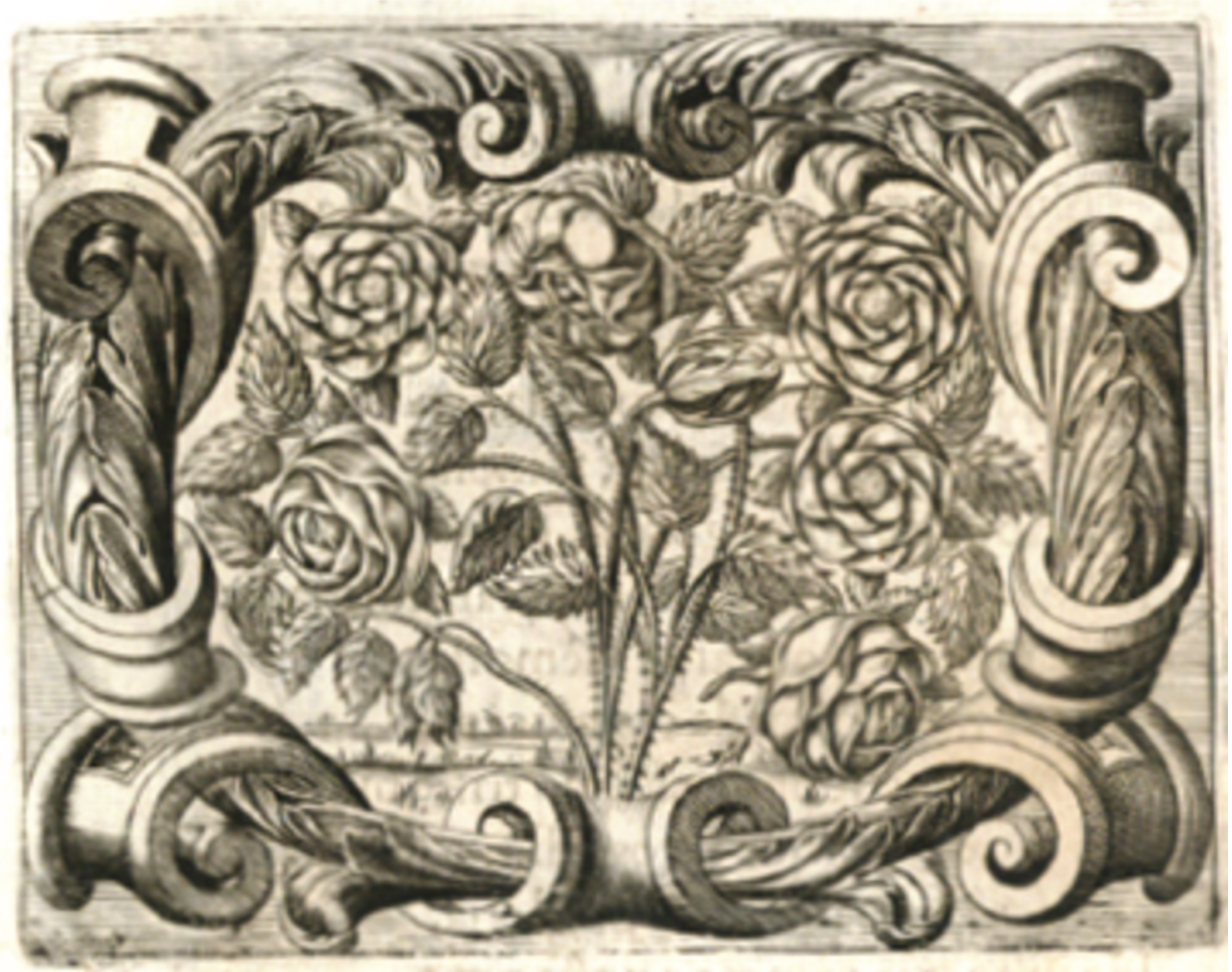

Fonte: PAIVA (1699, p. 6)

O exemplo anterior serve para corroborar a importância que as flores têm no imaginário popular e a simbologia das quais elas estão revestidas. As atribuições recebidas a cada uma das representações vêm sendo moldadas desde muito tempo, tanto que no Novecentos, começaram a surgir publicações destinadas a explicar aos seus leitores, os códigos e significados das flores. O primeiro manual surgiu na França e sua popularidade gerou novas publicações em vários países, inclusive no Brasil. Os temas eram variados, já que esses manuais davam suporte às "práticas de galanteria", incluindo outros itens que iam, desde objetos até atitudes pessoais. Havia um "riquíssimo e variado universo de diálogos codificados baseados no uso ensaiado de leques, chapéus, bengalas, luvas ou mesmo das mãos", mas a simbologia das flores era o mais famoso de todos (EL FAR, 2014, p. 405).

Nas investigações realizadas, o Diccionário da Linguagem das Flores, publicado na cidade de Lisboa, em 1869, fornece dados importantes para este estudo, por apresentar uma visão do século XIX, que foi confrontada com informações da publicação atual, o Livro de Ouro das Flores. Por meio das duas publicações, foram selecionadas as principais flores associadas com a temática da morte e seus significados, demonstrados no Quadro 1 a seguir. 
Linguagens - Revista de Letras, Artes e Comunicação - ISSN 1981-9943

Blumenau, v. 12, n. 2, p. 327-346, maio/ago. 2018

DOI: http://dx.doi.org/10.7867/1981-9943.2018v12n2p327-346

Quadro 1. Flores e seus significados

\begin{tabular}{|c|c|c|c|}
\hline $\mathrm{N}^{\mathrm{o}}$ & FLOR & SIGNIFICADO & OBS. \\
\hline 1 & $\begin{array}{l}\text { Abrótea } \\
\text { (Asphodelus } \\
\text { ramosus) }\end{array}$ & $\begin{array}{l}\text { Minhas saudades vos } \\
\text { seguirão ao túmulo. }\end{array}$ & $\begin{array}{c}\text { Na mitologia grega, era a flor sagrada do } \\
\text { Hades (submundo). }\end{array}$ \\
\hline 2 & Acanto & Imortalidade. & $\begin{array}{l}\text { Folha com espinhos; beleza ao lado da } \\
\text { dor. Ornato clássico de colunas coríntias. }\end{array}$ \\
\hline 2 & $\begin{array}{l}\text { Adonidas (Adonis } \\
\text { vernalis) }\end{array}$ & $\begin{array}{l}\text { Dolorosas lembranças; } \\
\text { dolorosas recordações. }\end{array}$ & $\begin{array}{l}\text { Segundo a mitologia, a flor foi originada } \\
\text { a partir do sangue de Adonis, morto por } \\
\text { um javali. }\end{array}$ \\
\hline 3 & $\begin{array}{c}\text { Aloés } \\
\text { (Aloe vera) }\end{array}$ & Amargura; desgosto. & $\begin{array}{l}\text { Por seu sabor muito amargo, é associada } \\
\text { ao desgosto. }\end{array}$ \\
\hline 4 & $\begin{array}{c}\text { Amarantho } \\
\text { (Amaranthus) }\end{array}$ & Imortalidade. & $\begin{array}{c}\text { Para os antigos, era a flor que ornava a } \\
\text { fronte dos deuses, como símbolo de } \\
\text { honra suprema. }\end{array}$ \\
\hline 5 & $\begin{array}{l}\text { Anêmona } \\
\text { (Anemone } \\
\text { japonica) }\end{array}$ & $\begin{array}{l}\text { Abandono; esquivança; } \\
\text { morte precoce. }\end{array}$ & $\begin{array}{l}\text { Lendária associação do vermelho de } \\
\text { suas pétalas com o sangue que Cristo } \\
\text { derramou na cruz. Flor de vida breve. }\end{array}$ \\
\hline 6 & $\begin{array}{c}\text { Chorão } \\
\text { (Salix babylonica) }\end{array}$ & Melancolia. & $\begin{array}{l}\text { Diz a tradição cristã que seus ramos } \\
\text { foram usados para golpear Jesus. Aos } \\
\text { chineses é símbolo da imortalidade. }\end{array}$ \\
\hline 7 & Coroa de flores & Recompensa da virtude. & $\begin{array}{l}\text { A coroa vista como uma recompensa. } \\
\text { Geralmente contém rosas. }\end{array}$ \\
\hline 8 & $\begin{array}{c}\text { Cravo roxo } \\
\text { (Dianthus } \\
\text { caryophyllaceae) }\end{array}$ & Sentimento. & $\begin{array}{l}\text { O cravo branco significa ingenuidade; o } \\
\text { vermelho, o amor; já o roxo significa } \\
\text { afeto com tristeza. }\end{array}$ \\
\hline 9 & $\begin{array}{l}\text { Cipreste } \\
\text { (Cupressus) }\end{array}$ & $\begin{array}{l}\text { Luto; ritos da morte; } \\
\text { renascimento ou vida } \\
\text { eterna. }\end{array}$ & $\begin{array}{c}\text { Os antigos o consagraram a Parcas } \\
\text { (divindades que controlavam o destino, } \\
\text { vida e morte dos mortais). }\end{array}$ \\
\hline 10 & $\begin{array}{c}\text { Flor de Liz } \\
\text { (Sprekelia } \\
\text { formosissima) }\end{array}$ & Majestade; fé; sabedoria. & $\begin{array}{l}\text { Símbolo de Maria, pela beleza e por ser } \\
\text { rainha do céu e da terra. Na heráldica, é } \\
\text { associada à monarquia francesa. }\end{array}$ \\
\hline 11 & $\begin{array}{l}\text { Flor do Maracujá - } \\
\text { Martírio } \\
\text { (Passiflora edulis) }\end{array}$ & $\begin{array}{l}\text { A Paixão de Cristo } \\
\text { (associação feita por } \\
\text { missionários europeus); } \\
\text { crença, fé e religião. }\end{array}$ & $\begin{array}{l}\text { Fruto da paixão (passion fruit, em } \\
\text { inglês), o formato da flor lembra a coroa } \\
\text { de espinhos, o açoite, a esponja, os } \\
\text { cravos e as cinco chagas de Cristo. }\end{array}$ \\
\hline 12 & $\begin{array}{c}\text { Helenio } \\
\text { (Inula Helenio) }\end{array}$ & Pranto. & $\begin{array}{l}\text { São tidas como as lágrimas de Helena de } \\
\text { Tróia que ao fecundaram ao cair no solo. }\end{array}$ \\
\hline 13 & $\begin{array}{c}\text { Palmeira } \\
\text { (Arecaceae) }\end{array}$ & $\begin{array}{l}\text { Folhas da palmeira: } \\
\text { Martírio; vitória sobre a } \\
\text { morte; imortalidade. }\end{array}$ & $\begin{array}{l}\text { Cristãos usam no Domingo de Ramos, } \\
\text { recordando a vitória de Cristo sobre a } \\
\text { morte. Atributo de santos mártires. }\end{array}$ \\
\hline 14 & $\begin{array}{l}\text { Perpétua } \\
\text { (Gomphrena } \\
\text { globosa) }\end{array}$ & $\begin{array}{l}\text { Lealdade; amizade. } \\
\text { A perpétua-roxa é } \\
\text { associada a morte. }\end{array}$ & $\begin{array}{c}\text { Flor que resiste ao tempo, mantendo } \\
\text { seus encantos mesmo depois de colhida. } \\
\text { Simboliza perenidade. }\end{array}$ \\
\hline 15 & $\begin{array}{l}\text { Rosa } \\
\text { (Rosa) }\end{array}$ & $\begin{array}{l}\text { Perfeição; amor; beleza. } \\
\text { É a rainha das flores. }\end{array}$ & $\begin{array}{l}\text { Cada cor simboliza um tipo de amor, } \\
\text { incluindo suas associações. Rosa branca } \\
\text { e vermelha simbolizam sofrimentos de } \\
\text { amor. Maria é a rosa sem espinhos. }\end{array}$ \\
\hline 16 & $\begin{array}{c}\text { Saudades } \\
\text { (Scabiosa } \\
\text { artropurpurea) }\end{array}$ & Saudade; viuvez. & $\begin{array}{l}\text { Também conhecida como flor-de-viúva, } \\
\text { por sua cor. Quando associada com a } \\
\text { Perpétua, significa perpétuas saudades. }\end{array}$ \\
\hline 17 & $\begin{array}{c}\text { Teixo } \\
\text { Taxus baccata) }\end{array}$ & Tristeza. & $\begin{array}{l}\text { Árvore que mata as plantas que a } \\
\text { cercam, pois lhe rouba os nutrientes. }\end{array}$ \\
\hline
\end{tabular}


Fonte: Elaborado pelos autores (2018)

\subsection{LINGUAGEM ALEGÓRICA: AS FLORES NA BRANCA MORTALHA ESPALHADA}

É importante traçar uma distinção entre os termos símbolo e alegoria. Embora usados desde a antiguidade clássica, suas diferenças só foram marcadas nos escritos de Goethe e Schlegel, no período Romântico. A palavra alegoria tem origem etimológica do grego, cujo significado é dizer algo, de maneira diferente do seu sentido literal, como forma de representar uma realidade com sentido figurado. É uma figura de linguagem usada não só na literatura, mas também nas artes visuais, como expressão de ideias, pensamentos e conceitos por meio de várias imagens ou metáforas. (CEIA, 2009).

O símbolo, por sua vez, estabelece uma relação direta com o seu objeto. É "um signo que se constitui como tal simplesmente ou principalmente pelo fato de ser usado e entendido como tal, quer o hábito seja natural ou convencional, e sem se levar em conta os motivos que originalmente governaram a sua seleção" (PEIRCE, 1958, p. 2.298). No símbolo, a ligação entre a imagem e o significado é percebida de maneira clara, o que já não ocorre com a alegoria, que apresenta uma relação arbitrária entre ambos, algo diferente de si mesma. Comprovou-se, neste estudo, que as flores além de simbólicas, podem também ser alegóricas.

As flores possuem uma forte associação com rituais e celebrações. São usadas em momentos alegres, seja adornando mesas de banquetes, embelezando ambientes sagrados e profanos, conduzidas por noivas em formato de bouquets ou como adornos de cabeça em cerimonias de casamentos, como presentes de aniversário, ou simplesmente para declarar um amor. Por outro lado, também são adornos na hora da morte.

Com exceção de algumas religiões, como é o caso do Judaísmo, em que o uso de flores em velórios é desencorajado (BEIT CHABAD, s/d), essas ornamentações são bemvindas em ambientes fúnebres. Um periódico ilustrado português de meados do XIX, denominado de Archivo Pittoresco, editado por Castro, Irmão \& $C^{\text {a }}$ (1865), menciona que se tratava de costume antigo, honrar com flores, os mortos, encontrando ressonância nos costumes da época, especialmente na Inglaterra. Para comprovação, o texto cita um poema a Ofélia, da peça Hamlet, de Shakespeare, que morreu afogada ao colher flores: As flores, na branca mortalha espalhada, / suavisam (sic), realçam, seu níveo candor!/ E ao tumulo 


\section{Linguagens - Revista de Letras, Artes e Comunicação - ISSN 1981-9943 \\ Blumenau, v. 12, n. 2, p. 327-346, maio/ago. 2018 \\ DOI: http://dx.doi.org/10.7867/1981-9943.2018v12n2p327-346}

descem; lá vão orvalhadas/ de prantos, nascidos de sincera dor! (ARCHIVO PITTORESCO, 1865. vol.8).

As flores são objetos de uma apropriação simbólica bastante recorrente. Elas indicam tanto o Paraíso, prefigurado no Jardim do Éden, quanto as estações do ano na terra. Desde a Idade Média, as flores assumiram um sentido particular dentro do ideário cristão. Por exemplo: flores vermelhas representavam o sangue da Paixão de Cristo; flores brancas, especialmente o lírio e a rosa sem espinhos, a pureza da Virgem. O ciclâmen, o jasmim, o lírio do vale e as violetas também eram relacionados à Virgem (CARR-GROM, 2004, p. 97).

Os jardins, segundo aponta a tradição, são lugares de contemplação e cultivo de flores, representam o Paraíso e a morada da alma. Seria uma representação do próprio Éden bíblico, símbolo da perfeição por ter sido criado por Deus, onde Adão e Eva viviam antes do pecado original. (BRUCE-MITFORD, 2001). Portanto, é comum a associação de flores como obrasprimas da criação divina:

\footnotetext{
Em todos os tempos e culturas, as flores sempre ocuparam lugar especial na vida e no coração das pessoas. Algumas eram vistas antigamente como formas terrenas dos deuses. Eram usadas nos cultos, e atribuíam-lhe poderes mágicos. Em botão, uma flor é símbolo de vida nova, mas também pode acompanhar um morto para o túmulo. (BRUCE-MITFORD, 2001. p. 50-51).
}

Algumas flores, comumente associadas à morte, são carregadas de simbologia judaicocristã e profana, como é o caso da rosa, miosótis (conhecida também como não-me-esqueças), anêmona, papoula, cravo-de-defunto e o lírio (BRUCE-MITFORD, 2001. p.51). O Quadro 2 contêm muitas espécies, cujos simbolismos têm inspiração na mitologia greco-romana.

Com base na pesquisa de campo no Cemitério da Soledade, algumas espécies de flores mereceram destaque, tanto em função da grande quantidade de exemplares encontrados, quanto por suas cargas simbólicas. Primeiramente, destaca-se a rosa, especificamente, pois esta flor revela duas representações: quando apresentada em formato de botão, significa a morte precoce, por exemplo de uma criança, já a rosa aberta exprime o falecimento de um adulto. Isso quer dizer que, a iconografia desta referida flor pode assumir significações diferentes, conforme o uso no jazigo.

Outra flor encontrada foi a Abrotéa, planta bulbosa de flores vistosas e caule comestível, pertencente à família asphodelaceae, originária da região do mediterrâneo (ENCYCLOPAEDIA BRITANNICA, 2017). Esse é, provavelmente, um dos motivos de sua associação com os mortos, pois havia um antigo costume grego de plantar estas flores ao lado 


\section{Linguagens - Revista de Letras, Artes e Comunicação - ISSN 1981-9943 \\ Blumenau, v. 12, n. 2, p. 327-346, maio/ago. 2018 \\ DOI: http://dx.doi.org/10.7867/1981-9943.2018v12n2p327-346}

das sepulturas, (ENCYCLOPEDIA OF LIFE, 2014), talvez pela ideia de que poderiam servir de alimento aos mortos.

$\mathrm{Na}$ mitologia grega, essa flor é associada à figura de Perséfone, que é comumente representada com uma guirlanda de asphodelus na cabeça. Considerada a deusa das ervas, flores, frutos e perfumes, filha de Zeus e Deméter, essa divindade foi raptada por Hades, quando colhia flores - narcisos, que a levou para o mundo dos mortos. Durante a primavera e o verão, Perséfone morava no Olimpo e no outono e inverno, voltava ao mundo dos mortos. Um dia, com ciúmes de Hades, transformou a ninfa Menthe em uma flor "destinada a vegetar nas entradas das cavernas, ou, em outra versão, na porta de entrada do reino dos mortos. Esta flor é a asphodelus. O "campo de asfodelos" é o lugar para onde deveriam ir as almas dos que morreram para serem julgados." (DIVINDADES GREGAS, 2004).

Outra flor com grande simbologia funerária e muito utilizada como elemento decorativo no Cemitério Soledade, em Belém/PA, no Campo Santo, em Salvador/BA, no Cemitério dos Prazeres e no Alto de São João, estes dois últimos em Lisboa/PT, é a flor denominada Perpétua, cujo nome científico é gomfrena globosa. Trata-se de uma planta herbácea que se apresenta com flores pequenas e de coloração arroxeada, nativa da Índia e conhecida no Brasil como perpétua-roxa. Esta espécie é também cultivada como planta ornamental (FANK-DE-CARVALHO, 2005).

O uso das Perpétuas nas esculturas e ornamentações de túmulos é bastante comum em Portugal. Por vezes, elas vêm associadas a outra flor denominada de Saudades, que juntas simbolizam a união dos nomes: perpétuas saudades. Monteiro (2012) explica que:

\footnotetext{
As Perpétuas são plantas conhecidas por florirem em canudinhos ou bolinhas conhecidas também pelo chá que se faz com elas: em especial, o de perpétuas roxas; favorito da fadista Amália - e a Saudade tem uma representação parecida com a do cardo, podendo até ser confundida com este. Juntas, não carecem de mais interpretação: significam "Perpétua Saudade" ou "Saudade Perpétua".
}

$\mathrm{Na}$ visita técnica realizada em novembro de 2013, ao Cemitério dos Prazeres e em julho de 2018 ao Cemitério Alto de São João, ambos em Portugal, observou-se o uso decorativo das flores "perpétuas e saudades", isoladas ou associadas, em várias sepulturas. Como vários túmulos do Cemitério da Soledade, em Belém/PA, são de procedência europeia, notadamente portuguesas, é possível que os modelos adotados fossem semelhantes aos dos cemitérios lusitanos, alguns deles adquiridos por meio de encomendas por catálogos a marmorarias de Portugal. 


\section{Linguagens - Revista de Letras, Artes e Comunicação - ISSN 1981-9943 \\ Blumenau, v. 12, n. 2, p. 327-346, maio/ago. 2018 \\ DOI: http://dx.doi.org/10.7867/1981-9943.2018v12n2p327-346}

$\mathrm{Na}$ Figura 2 destaca-se um exemplo da representação das Perpétuas Saudades, encontrada em túmulo no Cemitério dos Prazeres, em Lisboa, Portugal.

Figura 2. Escultura das flores Perpétua e Saudades, no Cemitério dos Prazeres (Lisboa/PT)

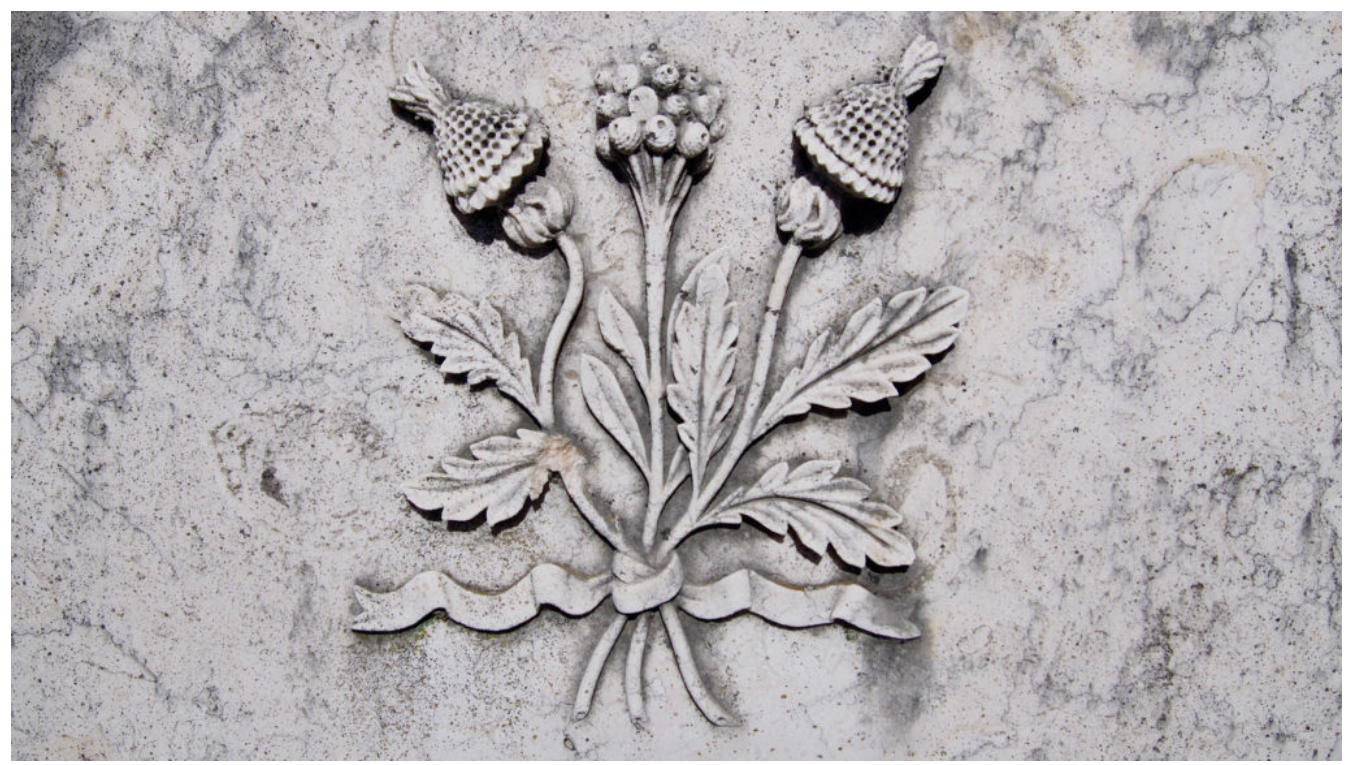

Fonte: Cosmic House (2018)

Então, pode-se destacar que, desde tempos remotos, as flores acompanham os rituais funerários. Foram encontradas flores pintadas decorando tumbas etruscas na Turquia e floresde-lótus nos sepulcros dos faraós do Egito. Além desses casos, foram descobertas catacumbas romanas com "muitos motivos florais simbólicos pintados por cristãos da Igreja primitiva" (SOARES, 2002). “A través de los tiempos el hombre tomó conocimiento del poder sugestivo de las flores. Las mismas se fueron empleando con fines más o menos alegóricos"^4 (MESA, 2009).

As flores dão vida à morte e acompanham os ritos funerários, a não ser que o defunto pertença a alguma religião que não permita este oferecimento ou homenagens (FINOL, 2001), como é o caso da religião judaica. Um artigo da revista Super Interessante (1988), corrobora a percepção de que as flores continuam sendo muito usadas na hora da morte até os dias atuais. Dizia o artigo que elas ainda "enfeitam as mesas durante as festas, homenageiam os que nascem, os mortos e os que se casam".

\footnotetext{
${ }^{4}$ Tradução do espanhol: Através dos tempos, o homem tomou consciência do poder sugestivo das flores. Eles foram usados para fins mais ou menos alegóricos.
} 


\subsection{O CASO DA LULU : UMA ROSA EM BOTÃO.}

Um túmulo, do Cemitério da Soledade, em Belém do Pará, foi selecionado para exemplificar de maneira prática o uso de flores como ícones funerários. Localizado na alameda principal que liga a portada à capela, o monumento funerário abriga os restos mortais de Luiza Calandrini Sarah Bond Dewey, filha de Henry Bond Dewey, Cônsul dos Estados Unidos no Pará (HERNDON; GIBBON, 1854), que se casou com uma paraense.

O túmulo apresenta estilo Neoclássico (Figura 03), com base alongada, de secção quadrada, que sustenta urna funerária em forma de vaso parcialmente coberto por um panejamento de influência greco-romana, onde se lê o apelido "Lulu" e as datas de seu nascimento e de sua morte. No centro da pequena base curvada, sob a urna, há a representação de uma ampulheta com asas, ladeada nas extremidades do monumento por folhas de acanto.

A ampulheta alada faz alusão à passagem do tempo, inexorável e veloz. Nas laterais, as folhas de acanto chanfradas são elementos clássicos associados à beleza e à dor, uma vez que esta é planta espinhosa de folhas recortadas. Contudo, a principal representação simbólica encontrada é a imagem solitária de uma pequena rosa em botão quebrada, localizada abaixo dos demais elementos citados. 


\section{Linguagens - Revista de Letras, Artes e Comunicação - ISSN 1981-9943 \\ Blumenau, v. 12, n. 2, p. 327-346, maio/ago. 2018 \\ DOI: http://dx.doi.org/10.7867/1981-9943.2018v12n2p327-346}

Figura 3. Túmulo de Luiza Calandrini Dewey

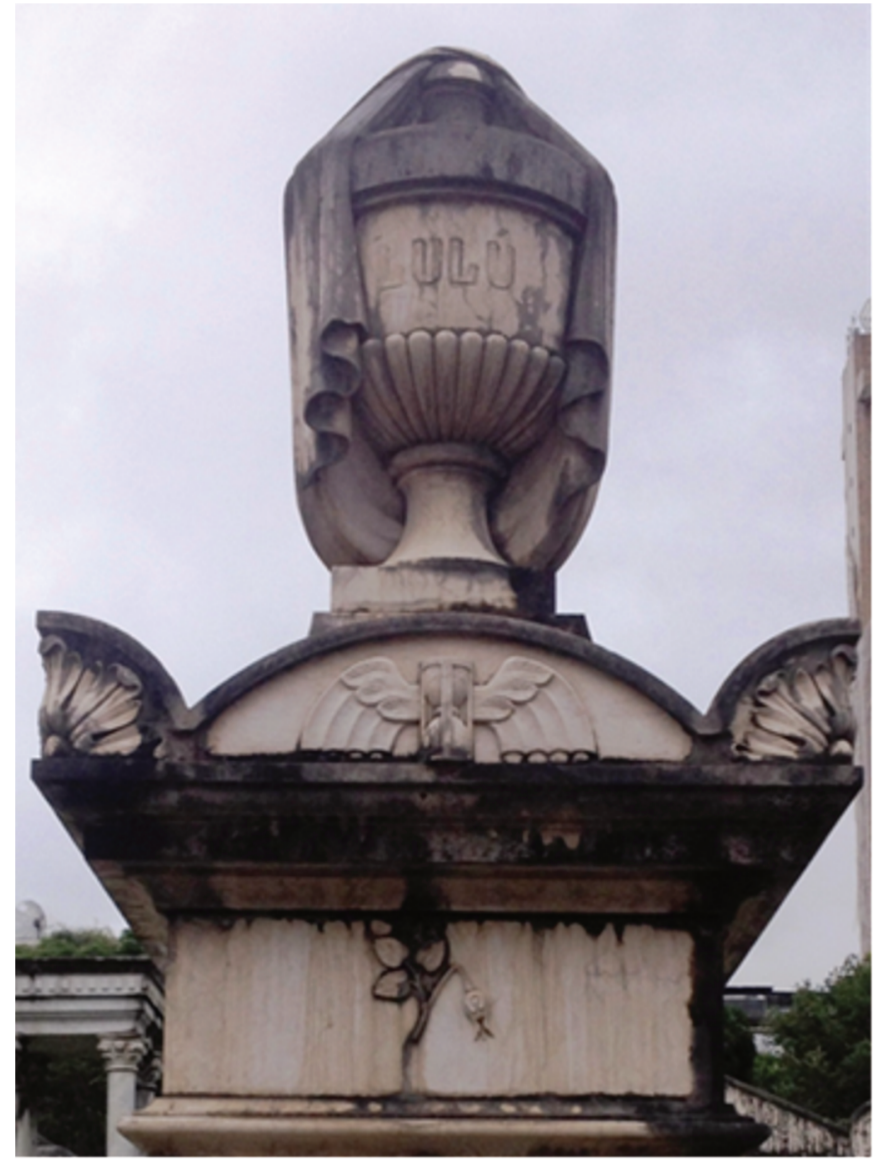

Fonte: Autores (2014).

O poeta lírico Anacreon conta que as primeiras rosas floresceram por ocasião do nascimento de Vênus, a deusa da beleza, chamada de Afrodite pelos romanos. Daí a associação desta flor à beleza, pois a mais bela das mulheres deveria estar acompanhada da mais bela das flores, cuja representação simbólica está relacionada ao amor e à perfeição. Vários buquês de rosas foram encontrados no sarcófago do Faraó Tutankhamon e, em suas obras, Shakespeare cita pelo menos setenta vezes esta flor. (SOARES, 2002. p. 230-231).

As pinturas de naturezas-mortas, denominadas de vanitas, tentavam traduzir simbolicamente a angústia do homem perante a morte. Era comum o uso de frutas e flores, dentre elas, a rosa, com o indício de que tanto a vida quanto a beleza são efêmeras. No Medievo, a rosa vermelha recebeu a associação com o sangue dos justos, a começar pelo próprio sangue de Cristo. A representação da flor, no meio dos espinhos, recordava os mártires cercados de seus perseguidores. No jardim do Éden, a rosa que ali florescia não possuía espinhos (CARR-GROM, 2004. p. 193 - 194), pois naquele lugar não havia tristeza nem dor. 


\section{Linguagens - Revista de Letras, Artes e Comunicação - ISSN 1981-9943 \\ Blumenau, v. 12, n. 2, p. 327-346, maio/ago. 2018 \\ DOI: http://dx.doi.org/10.7867/1981-9943.2018v12n2p327-346}

A rosa sem espinhos é o tipo de flor associado à Virgem Maria, pois a tradição católica preconiza o dogma da Imaculada Conceição, ao afirmar que ela foi concebida sem o pecado original. Dados, a partir do século XIII, revelam a existência de referências da devoção mariana denominada de Rosarium Virginis Mariae. Trata-se de um conjunto de orações, recordando os mistérios da vida de Cristo, em que cada Ave-Maria rezada simboliza uma rosa espiritual ofertada à Virgem. O Rosário, no sentido místico, representa “o jardim de rosas de Maria.” (SOARES, 2002. p. 230).

A pequena rosa em botão que parece pender de um caule quebrado, possivelmente associa a falecida Luiza, cujo apelido era "Lulu", a uma flor que não teve chance de desabrochar, pois morreu antes dos três anos de idade (RODRIGUES, 2014). Seus pais tinham certeza de que ela seria uma bela mulher, representada pela rainha das flores, mas que não pôde ser contemplada em sua plenitude, já que morreu criança. Recorda-se que, durante o tempo em que o Cemitério da Soledade esteve em funcionamento, entre 1850 e 1880, ocorreram duas epidemias na cidade: a de febre amarela e a de cólera. (VIANNA, 1975). Logo, deduz-se que a criança tenha sido uma de suas vítimas.

Para fazer um contraponto com o túmulo de Lulu, selecionou-se outro exemplar do mesmo Cemitério, com uma diferente representação iconográfica do mesmo elemento, a rosa. O monumento funerário em honra a D. Antônia Joaquina Roiz dos Santos é uma estela em baixo-relevo, executado em mármore de Lioz, também em estilo Neoclássico (Figura 4). O túmulo apresenta a escultura de um casal em trajes clássicos, revelando dor e lamentação. A mulher descansa a cabeça no ombro do homem e destaca-se uma grande rosa quebrada que a figura masculina segura na mão direita. Ao contrário de Lulu, que teve a vida ceifada precocemente, D. Antônia atingiu sua plenitude. A rosa grande está aberta e revela, aos que passam por sua sepultura, que ali jaz uma mulher, que em vida, foi muito bonita e muito amada. 
Figura 4. Túmulo de D. Antônia Joaquina Roiz dos Santos

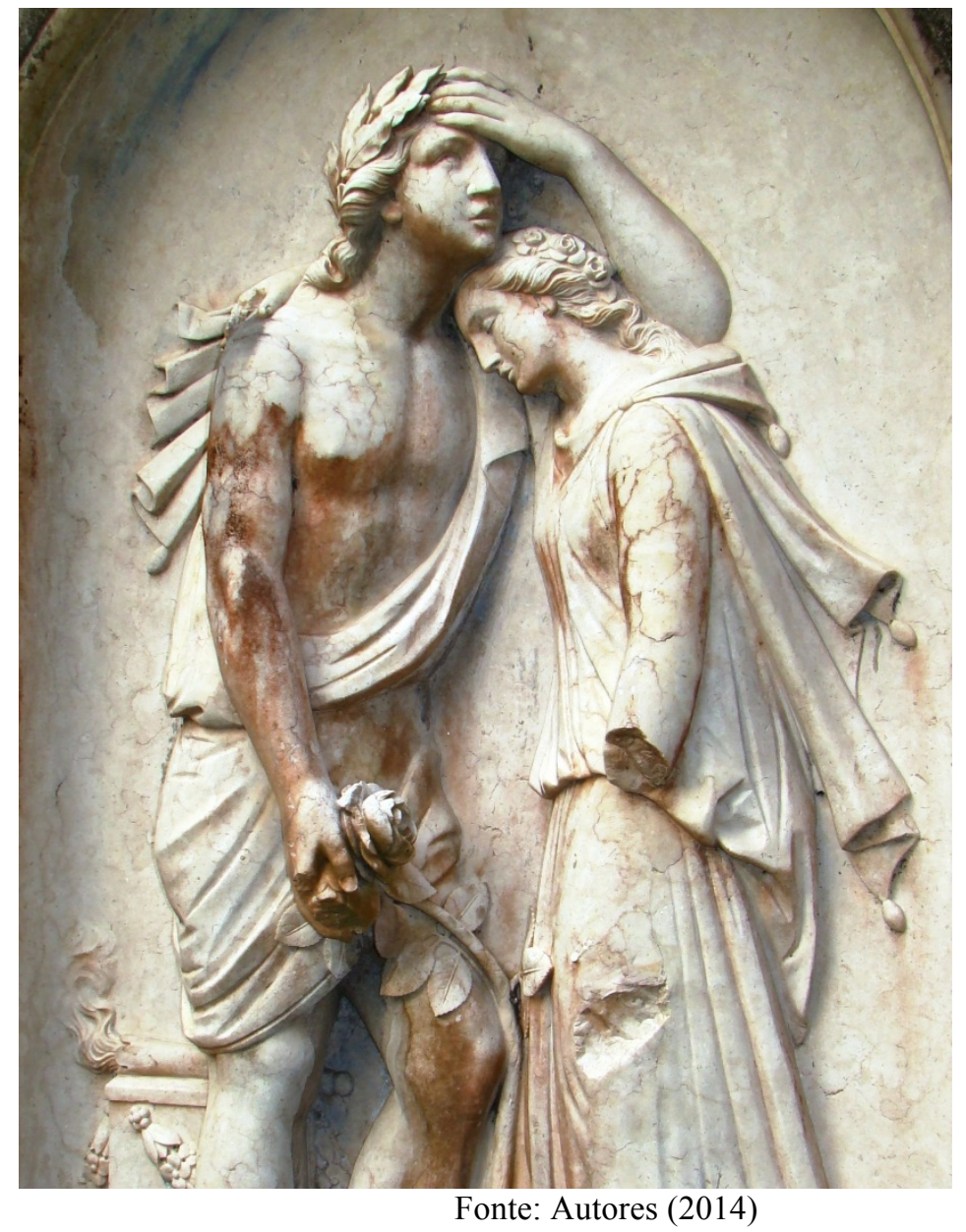

A beleza de Lulu e de Dona Antônia foi igualmente exaltada a partir da escolha da rosa como iconografia funerária. Em ambos os casos, a morte é representada, nos túmulos, pela haste da flor quebrada. Contudo, a diferença de idades entre elas está codificada por meio da representação floral em diferentes estágios de sua existência: uma das rosas já se apresenta completamente aberta, totalmente desenvolvida, enquanto a outra flor ainda está fechada, em botão.

\section{CONCLUSÃO: TRAGO-TE FLORES}

A morte pode ser vista como um tabu da atualidade, visto que se conversa abertamente sobre costumes, preconceitos, crimes, escândalos e sexualidade, mas ainda pouco do inevitável fim. Como fenômeno físico, o falecimento do corpo e os processos de finitude da vida têm sido largamente estudados, porém, seus aspectos socioculturais são pesquisados e 


\section{Linguagens - Revista de Letras, Artes e Comunicação - ISSN 1981-9943 \\ Blumenau, v. 12, n. 2, p. 327-346, maio/ago. 2018 \\ DOI: http://dx.doi.org/10.7867/1981-9943.2018v12n2p327-346}

propagados em menor escala. Foucault (2012) já percebia este fato ao mencionar a "desqualificação da morte", exemplificada pelo crescente abandono dos ritos funerários.

Ao longo da História, percebem-se diferentes maneiras do homem ao encarar a sua morte e a morte dos outros. Kovács (1992, p. 16) afirma que, para o ser humano, o temor "é a resposta psicológica mais comum diante da morte". É inegável que a temática gera desconforto, especialmente para uma sociedade contemporânea ocidental que frequentemente usa mecanismos de afastamento da morte, tanto no plano individual como coletivo. Todavia, as reflexões sobre as representações da morte, sua simbologia, seus ritos e seus aspectos culturais, configuram-se como um promissor campo de pesquisas, face às diferentes abordagens interdisciplinares que podem ser realizadas.

Para Le Goff (2003), a memória é resultado de um conjunto de funções psíquicas que torna possível ao indivíduo conservar determinadas informações, através de uma espécie de atualização ou reinterpretação de impressões ou informações passadas. A Memória Coletiva surge, portanto, quando as lembranças individuais passam a ser vistas como propriedade da coletividade, ou de um grupo, construindo identidades. A Memória Coletiva seria como uma luta das "forças sociais" pelo poder, em que discussões da memória e do esquecimento são vistas como uma forma de dominação. Estas bases teóricas reafirmam o importante papel da memória coletiva, presente em cemitérios públicos e a importância de conhecimentos, nesta área, para o profissional que deseja atuar, seja em projetos de conservação, restauração ou qualquer outra intervenção em necrópoles com valor histórico, artístico e cultural.

Os percursos semióticos percorridos por este artigo aprofundaram questões acerca das possibilidades de cognição e comunicação, a partir de linguagens não verbais construídas dentro de cemitérios, entre flores e a morte. Contudo, as questões de análises sígnicas não devem ser revestidas de caráter definitivo, uma vez que há toda uma dinamicidade que os envolvem e dependem do ponto de vista do observador desses signos e dos contextos culturais envolvidos.

Não há nenhum critério apriorístico que possa infalivelmente decidir como uma dada semiose [ação do signo] funciona, pois tudo depende do contexto de sua atualização e do aspecto pelo qual ela é observada e analisada. Enfim, não há receitas prontas para a análise semiótica. Há conceitos, uma lógica para sua aplicação. [...] (SANTAELLA, 2002, p. 43)

As flores que Machado de Assis levou à sua Carolina foram metaforizadas: viraram poéticas. É possível encontrar poesia nas representações iconográficas das flores como 


\section{Linguagens - Revista de Letras, Artes e Comunicação - ISSN 1981-9943 \\ Blumenau, v. 12, n. 2, p. 327-346, maio/ago. 2018 \\ DOI: http://dx.doi.org/10.7867/1981-9943.2018v12n2p327-346}

objetos funerários, que ainda podem ser contempladas em cemitérios monumentais do século XIX. São relações icônicas, indiciais e simbólicas à espera de um "leitor", visto que a linguagem das flores narra histórias, celebra vivências, exalta virtudes, enfim, cria uma comunicação entre um objeto, seu signo e alguém que esteja disposto a entendê-lo. São formas de maior compreensão de um objeto pretérito na contemporaneidade.

Os cemitérios-parques da atualidade, limitados a lápides perfiladas, simétricas e produzidas industrialmente, perderam um importante canal de comunicação entre mortos e vivos: as relações simbólicas dos signos, nas quais representações simbólicas se tornam esperanças de imortalidade. Posto que as pessoas são "animais de linguagem", a morte pode representar o fim para os materialistas, no entanto, a representação iconográfica das flores nos túmulos dos cemitérios, aponta para a eternização e a imortalidade pretensa. Representar flores é, em suma, espantar o medo da finitude e este artigo proclama: "Trago-te flores, flores do jardim deste campo santo", afinal, as flores são estampas que imortalizam a vida humana.

\section{REFERÊNCIAS}

\section{ARCHIVO PITTORESCO. Semanario ilustrado. Volume VIII, 1865.}

BEIT CHABAD: Sua referência judaica na internet. Disponível em: http://www. chabad.org.br. Acesso em: 10 abr. 2020.

BENJAMIN, Walter. O narrador. Considerações sobre a obra de Nikolai Leskov. In: BENJAMIN, Walter. Magia e técnica, arte e política. Ensaios sobre literatura e história da cultura. Obras escolhidas. vol. I. São Paulo: Brasiliense, 2004.

BRUCE-MITFORD, Miranda. O livro ilustrado dos símbolos: o universo das imagens que representam as ideias e os fenômenos da realidade. Trad. Fernando Wizard e Maria Rodrigues. São Paulo: Publifolha, 2001. p. 50-51.

CALHEIROS, Luiz. Entradas para um Dicionário de estética. In: Vanitas. Disponível em: http://www.ipv.pt/millenium/pers13_4.htm Acesso em: 02ago2018.

CARR-GROMM, Sarah. Dicionário de símbolos na arte: guia ilustrado da pintura e da escultura ocidentais. Trad. Marta de Senna. Bauru, SP: EDUSC, 2004.

CEIA, Carlos. Sobre o conceito de alegoria. In: E-Dicionário de Termos Literários. Disponível. 2009. Disponível em: http://www.pgletras.uerj.br/matraga/nrsantigos/ matraga10ceia.pdf. Acesso em: 22 fev. 2019.

CHEVALIER, Jean; GHEERBRANT, Alain. Dicionário de símbolos. Rio de Janeiro: José Olympio, 1998. 


\section{Linguagens - Revista de Letras, Artes e Comunicação - ISSN 1981-9943 \\ Blumenau, v. 12, n. 2, p. 327-346, maio/ago. 2018 \\ DOI: http://dx.doi.org/10.7867/1981-9943.2018v12n2p327-346}

COSMIC HOUSE. Perpétua: símbolo da imortalidade e eternidade. Disponível em: http://www.cosmichouse.tziki.net/simbologia-no-cemiterio-dos-prazeres Acesso em: 01 mar. 2019.

CYMBALISTA, Renato. Cidades dos vivos: arquitetura e attitudes perante a morte nos cemitérios do Estado de São Paulo. São Paulo: Annablume: Fapesp, 2002.

DICIONÁRIO DA LINGUAGEM DAS FLORES. Ornado com estampas coloridas. 3. ed. Lisboa: Tipografia Lusitana, 1868. Disponível em: http://purl.pt/13929/1/ index.htm 1\#/11/html. Acesso em: 05 jul. 2018.

DICIONÁRIO HISTÓRICO, COROGRÁFICO, HERÁLDICO, BIOGRÁFICO, BIBLIOGRÁFICO, NUMISMÁTICO E ARTÍSTICO. Volume IV, págs. 842-843. Disponível em: http://www.arqnet.pt/ dicionario/mariasofia_neuburgo.html. Acesso em: 07 mar. 2019.

EL FAR, Alessandra. Uma etnografia do galanteio nos terrenos da ficção: afinidades eletivas entre antropologia e literatura. Revista de Antropologia, São Paulo, v. 57, n.1, p. 393-422, 2014.

ENCYCLOPAEDIA BRITANNICA. Asphodel. Disponível em: https://www. britannica.com/ plant/asphodel-plant. Acesso em: 02 ago. 2018.

EOL - ENCYCLOPEDIA OF LIFE. Asphodelus. Disponível em: http://eol.org/ pages/32870 /details. Acesso em: 02 ago. 2018.

FANK-DE-CARVALHO, Suzane Margaret; GRACIANO-RIBEIRO, Dalva. Arquitetura, anatomia e histoquímica das folhas de Gomphrena arborescens Lf (Amaranthaceae). Acta Bot. Bras., São Paulo, v. 19, n. 2, p. 377-390, jun. 2005. Disponível em http://www.scielo.br/scielo.php?script=sci_arttext\&pid=S010233062005000200021\&lng=en\&nrm=iso. Acesso em: 10 abr. 2020.

GRAVIERS, B. des \& JACOMET, T. Os santos e seus símbolos. São Paulo: Folio, 2003.

HERNDON, William Lewis; GIBBON, Lardner. Exploration of the valley of the Amazon. Washington: Robert Armstrong Public Printer, Vol.2, 1854. Disponível em: http://books.google.com/books?isbn=5876039233. Acesso em: 10 mar. 2019.

FOUCAULT, Michel. História da sexualidade 1: a vontade de saber. Rio da Janeiro: Graal, 2012.

KOVÁCS, Maria Júlia. Morte e desenvolvimento humano. 2. ed. São Paulo: Casa do Psicólogo, 1992.

LE GOFF, Jacques. História e memória. 3. ed. Tradução de Irene Ferreira, Bernardo Leitão e Suzana Ferreira Borges. Campinas: UNICAMP, 1994.

MESA, Alejandro. ¿De qué nos están hablando los símbolos del Cementerio Viejo? Paysandú, Uruguay, jan/2009. 
MONTEIRO, Gisela. Blog Mort Safe. Simbologia: perpétua saudade. Publicado: 10/ 11/2012. Disponível em: http://taphophilia.blogspot.com/2012/11/simbologia-perpetua saudade.html. Acesso em: 02 fev. 2019.

MUMFORD, Lewis. A cidade na história: suas origens, transformações e perspectivas. Tradução: Neil R. da Silva. 4. ed. São Paulo: Martins Fontes, 1998.

PANOFSKY, Erwin. Tomb sculpture. Four lectures on its changing aspects from ancient egypt to Bernini. New York: Harry N. Abrams, Inc., 1992.

PAYVA, Sebastião da Fonseca e. Relaçam da magnifica, e sumptuosa pompa fvneral Com que o Real Convento de Palmella da Ordem Militar de Santiago, celebrou as Exequias da Serenissima Rainha N. Senhora D. Maria Sofia Isabel de Neobvrg. Lisboa: Oficina dos Herdeiros de Domingos Carneiro, 1699. Disponível em: http://purl.pt/23283/3/\#/10. Acesso em: 10 abr. 2010.

PEIRCE, Charles Sanders. The collected papers. Cambridge, MA: Harvard University Press, 1958.

PORTAL DA HISTÓRIA. Portugal Dicionário Histórico. Maria Sofia Isabel de Neuburgo. Disponível em: http://www.arqnet.pt/dicionario/mariasofia_neuburgo.html. Acesso em: 02 mar. 2018.

REVISTA SUPER INTERESSANTE. Quando falam as flores: chaves de um código. Abr./1988. Disponível em: http://super.abril.com.br/cultura/quando-falam-flores-chavescodigo-4 38551.shtml. Acesso em: 10 abr. 2020.

RODRIGUES, P. A. C. O tempo e a pedra. Belém/PA, 2003

SACKS, Oliver. O rio da consciência. Tradução: Laura Teixeira Motta. São Paulo: Companhia das Letras, 2017.

SANTAELLA, Lúcia. O que é semiótica. 3. ed. São Paulo: Brasiliense, 1985.

SOARES, Cecília Beatriz L. da Veiga. O livro de ouro das flores. Rio de Janeiro: Ediouro, 2002.

THE FLOWER EXPERT. Flowers \& religion. Disponível em: https://www. theflowerexpert.com/content/miscellaneous/flowers-and-religion. Acesso em: 01 ago. 2018.

VIANNA, Arthur. As epidemias no Pará. 2. ed. Belém: UFPA, 1975 [1908].

VOVELLE, Michel. Imagens e imaginário na história. São Paulo: Ática, 1997. 